\title{
A Farinha de Rami como sucedâneo da Farinha de Fêno da Alfafa, na alimentação de pintos
}

\author{
PROF. ALCIDES DI PARAVICINI TORRES \\ E. S. A. L. Q. - U. S. P. \\ ENG. AGR. JULIO CESAR MEDINA \\ I. A. - Campinas
}

INDICE

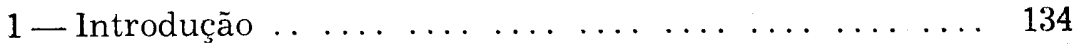

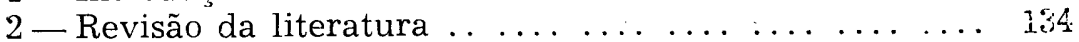

3 - Material e métodos . . . . . . . . . . . . . . . . . . . . . 135

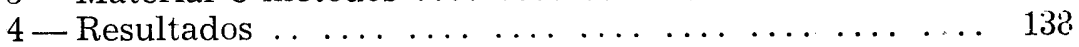

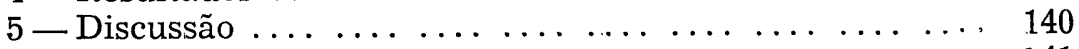

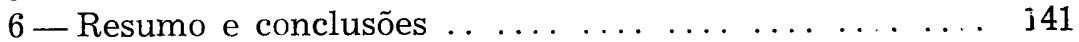

$\begin{array}{llllllllll}7 \text {-Abstract } \ldots \ldots & \ldots & \ldots & \ldots & \ldots & \ldots & \ldots & \ldots & \ldots & \ldots\end{array}$

$\begin{array}{llllllllll}8 \text { - Bibliografia } & \ldots & \ldots & \ldots & \ldots & \ldots & \ldots & \ldots & \ldots & \ldots\end{array}$

$\begin{array}{llllllllll}9 \text { - Agradecimentos } \ldots & \ldots & \ldots & \ldots & \ldots & \ldots & \ldots & \ldots & \ldots & \end{array}$ 


\section{1 - INTRODUÇÃO}

O Rami, cujo nome botânico é Boehmeria nivea Gaụd (Urtica nivea L.), é uma planta da família Urticacea, nativa da China, Japão e Ilhas Malaias. Desenvolve-se bem nas regiões tropicais e subtropicais, particularmente nos solos férteis e leves (silico-argilosos) atingindo uma altura de 90 a $180 \mathrm{~cm}$. E' tradicionalmente cultivada como planta produtora de fibras, contudo é também usada como ornamental e forrageira.

Em diversos países tropicais vem sendo usada para produzir forragem verde (de corte), fêno e mesmo pastagem, como um sucedâneo da Alfafa, particularmente onde o cultivo desta última espécie é mais difícil. E' que seu valor nutritivo tem-se mostrado equivalente ou superior ao da Alfafa e sua cultura, em determinadas condições, mais fácil e dando maiores produções.

No geral o fêno de Rami deverá ser considerado um subproduto de sua exploração para fibras, aproveitando-se os ponteiros e as fôlhas. Um hectare de Rami produz 60 toneladas de ramas, da quais 30 podem ser fenadas dando mais ou menos 7,5 toneladas. $O$ valor comercial dêsse subproduto atingiria a Cr\$30.000,00 ou mais por He., por ano. Nos anos de mau preço para a fibra, o rami poderia ser cortado mais frequentemente e a menor altura, rendendo então o dôbro como forragem. Considerando-se o alto preço da Alfafa no mercado interno, é plenamente justificável cultivar o Rami como planta forrageira exclusiva se de fato se comprovar que a substituição é conveniente.

Um de nós, já conhecedor por observações próprias da boia aceitação do Rami pelas diferentes espécies domésticas e interessado em incrementar sua cultura, como Chefe da Secção de Plantas Fibrosas, do Instituto Agronômico de Campinas, sabedor da grande dificuldade que as fábricas de rações e granjei. ros enfrentavam para adquirir farinha de Alfafa de boa qua.lidade, recorreu à 2a. Secção Técnica de Zootecnia da Escola Superior de Agricultura "Luiz de Queiroz" para realizar provas biológicas que confirmassem experimentos já existentes em outros países.

\section{2 - REVISÃO DA LITERATURA}

Embora tivéssemos conhecimento de ter sidı a farinha cie fêno de Rami estudada em vários países nos últimos anos, no momento da redação do presente trabalho contamos com pou- 
cas referências. Entre estas destacamos um bom trabalho de MEHRHOF, DAVIS e DRIGGERS (1950), na Estação Experimental de Agricultura da Universidade da Flórida (Gainesville). Numa primeira parte do experimento, êsses autores procuraram determinar a proporção ótima de farinha de Rami, substituindo a farinha de Alfafa. Usaram uma ração testemunha com $6 \%$ de farinha de Alfafa, comparada com outras 6, 9 e $12 \%$ de farinha de Rami e uma com $6 \%$ de farinha de Rami peneirada. Os melhores resultados no desenvolvimento e na eficiêricia de aproveitamento foram obtidos com as rações contendo 6 e $9 \%$ de farinha de Rami. Não foi demonstrada a diferen ${ }_{5} a$ estatística. Num segundo experimento houve uma ligeira vantagem dos lotes que receberam $6 \%$ de farinha de Rami. Concluíram que a farinha de Rami em misturas completas para frangos até 10 semanas compara-se favoràvelmente à farinha de fôlhas de Alfafa em relação ao consumo de alimento, eliciência no aproveitamento e mortalidade. A presença de fibrass longas na ração com farinha de Rami tornou sua mistura dif $\mathrm{l}^{-}$ cil, porém não prejudicou o consumo nem o rendimento da ração.

MORRISON (1950) se refere à farinha de Rami (fôlhas e pontas desidratadas) como um produto semelhante à farinha de alfafa ou de fôlhas de-Alfafa, com 17 a $24 \%$ de proteina e 15 a $26 \%$ de fibra, tendo já na época conhecimento de que DAVIS, na Flórida, a tinha usado com sucesso na alimentação de pintos em substituição à farinha de fôlhas de Alfafa.

\section{3 - MATERIAL E MÉTODOS}

A farinha de Rami foi preparada por um dos autôres na Secção de Plantas Fibrosas no Instituto Agrônomico de Campinas por simples secagem das fôlhas ao sol e subsequente moagem em moínho de palhetas. A farinha produzida apresentava-se fina, de odor agradável e côr verde escura, indício de seu provável teor elevado de caroteno. Aparentemente o material continha muito pouca fibra, o que se confirmou pelas análises realizadas na Escola Superior de Agricultura "Luiz de Queiroz". Assim deveria ser considerada uma farinha de fôlhas de Rami" e não pròpriamente de "ponteiros".

O material foi enviado ao prof. Tufi Coury, Chefe da Secção Técnica de Química Agrícola (E. S. A. L. Q.) para análise. Os resultados encontram-se na coluna I, do Quadro I.

Comparando-se êstes dados com os df. outros aidtôres (MORRISON, 1950; MEHRHOF, DAVIS e DRIGGERS, 1950) 
verifica-se que a amostra empregada apresentava um teor muito mais alto de minerais. A análise das cinzas, que constituiam $40,32 \%$ da matéria sêca, revelou nesta Escola:

\begin{tabular}{|c|c|c|}
\hline \multicolumn{3}{|c|}{ SiO2 (insolúveis e não determ.) } \\
\hline $\mathrm{P} 2 \mathrm{O} 5$ & (fósforo) & $0,907 \%$ \\
\hline $\mathrm{K} 2 \mathrm{O}$ & (potássio) & $3,277 \%$ \\
\hline & (cálcio) & $15,728 \%$ \\
\hline & Total cinzas & $40,32 \%$ \\
\hline
\end{tabular}

Pode-se explicar pois o excesso de minerais como sendo solo aderente às fôlhas, ou durante a vegetação ou durante o corte e secagem. Essa condição deve ser considerada como normal na prática. $O$ baixo teor de proteína na amostra utilizada no experimento é em parte atribuída ao alto teôr de minerais e

QUADRO I

Composição da Farinha de Rami

\begin{tabular}{|c|c|c|c|c|c|c|}
\hline & & & Anál & & & \\
\hline & I & II & III & & IV & \\
\hline Umidade & 11,12 & 12,45 & 7,8 & 10,48 & a & 4,37 \\
\hline Proteína bruta & 12,33 & 15,85 & 192 & 17,38 & a & 22,43 \\
\hline Matéria graxa & 8,23 & 7,55 & 3,8 & 3,14 & $\mathrm{a}$ & 6,00 \\
\hline Fibra bruta & 11,44 & 15,39 & 20.1 & 12,23 & $\mathrm{a}$ & 26,28 \\
\hline Minerais & 40,32 & 23,57 & 13,2 & 10,29 & a & 17,06 \\
\hline Extrat. não nitroger & $.16,56$ & 25,19 & 35,9 & - & & - \\
\hline $\mathrm{Ca}$ & 11,23 & $\ldots$ & 4,32 & 2,57 & $\mathrm{a}$ & 4,88 \\
\hline $\mathrm{P}$ & 0,28 & -_ & 022 & 0,21 & a & 0.27 \\
\hline $\mathrm{Mg}$ & - & -. & $\ldots$ & 0,45 & a & 0,82 \\
\hline Vit. A/U.S.P./100g & 26.666 & - & - & 44.000 & $\mathrm{a}$ & 47.000 \\
\hline Riboflavina $\mathrm{mg} / \mathrm{kg}$ & - & - & - & 7,7 & $\mathrm{a}$ & 15,0 \\
\hline Ácido Pantotênico & - & - & - & 26,4 & & \\
\hline Tiamina & - & - & - & 2,6 & a & 3,1 \\
\hline $\begin{array}{l}\text { Proteína di } \\
\text { Nutrientes } \\
\text { R. N. }\end{array}$ & $\begin{array}{l}\text { Sestível } \\
\text { digestív }\end{array}$ & $\begin{array}{l}\text { V) } \\
\text { tota }\end{array}$ & (IV) & & $\begin{array}{l}, 0 \% \\
2,3 \%\end{array}$ & \\
\hline
\end{tabular}

I Análise da E.S.A.L.Q., Laboratório da Secção de Química Agrícola, Piracicaba, São Paulo.

II Análise do Departamento de Nutrição Animal. Secção de Nutrição Animal. São Paulo.

III Dados de Morrison (1950), in "Feeds and Feeding".

IV Dados de Mehrhof e cols. (1950), de Gainesville, Flórida. 
também um pouco de umidade. O baixo teor de fibra pode ser explicado por tratar-se de farinha de fôlhas e retirada de algumas fibras mais longas no processo de moagem. Aliás, uma das dificuldades na preparação da farinha de Rami, já apontada por MEHRHOF e cols. (1950) é a resistência à moagem das fibras dos ponteiros, que embolam na farinha e dificultam sua mistura com os demais componentes, o que sugere a necessidade de peneirá-las. A farinha de Rami obtida por aquêles autôres, depois de peneirada, revelou a seguinte composição centesimal :

$\begin{array}{lr}\text { Matéria sêca } & 89,52 \\ \text { Proteína } & 22,43 \\ \text { 'Graxa } & 3,31 \\ \text { Cinzas } & 10,29 \\ \text { Fibras } & 12,23 \\ \text { Cálcio } & 2,5 \\ \text { Fósforo } & 0.21 \\ \text { Magnésio } & \mathbf{0 , 4 5}\end{array}$

Observe-se que o teor de fibra é equivalente ao da amostra usada neste experimento.

Julgamos que na industrialização em larga escala dos "ponteiros" de Rami, poder-se-ia usar picadores de facas capazes de cortar a fibra de rami em vez de esfacelá-la, antes de submeter o material a uma secagem artificial. O rendimento, economia de fôrça e mão de obra seriam necessàriamente maiores. Esta questão deve ser considerada na aplicação dos resultados dêste experimento.

O fêno de alfafa usado neste experimento como contrôle foi produzido na Secção de Fitotecnia da E.S.A.L.Q. e peló seu aspecto pareceu-nos bem representativo do tipo comercial de boa qualidade usado pelas fábricas de ração, por cujo motivo deixamos de mandar efetuar a análise química.

$O$ experimento foi iniciado em 5-7-56, com 190 pintos da raça White American, provenientes do Rio de Janeiro, que passaram dois dias em jejum aproximadamente. Após eliminação de 10 pintos considerados refugos, os restantes, de ambos os sexos, foram tomados de 4 em 4 distribuídos ao acaso em 4 divisões de uma bateria, aquecida a eletricidade e de temperatura regulável.

Os lotes A e A' receberam a ração básica misturada com $5 \%$ de alfafa moída e os lotes $\mathrm{B}$ e B' receberam $5 \%$ de farinha de rami misturada à ração básica. Os grupos $\mathrm{A}$ e A' foram formados pelos pintos colocados nos dois primeiros andares e como 
"contrôles" seriam beneficiados por qualquer influência de posição devido a melhor iluminação. A ração básica foi reistivamente simples, não se fazendo senão correções mínimas pa ra acentuar a diferença entre os tratamentos. Constọu da seguinte mistura :

Milho amarelo moído
Farelo de trigo grosso
Farelo de trigo fino
Farelo de algodão (inferior)
Farelo de amendoim
Farinha de carne de $50 \%$

Total
44 partes

10 partes

20 partes

7 partes

7 partes

7 partes

95 partes

Às misturas foi ainda adicionada uma mistura vitamínicomineral consistindo de apenas $13 \mathrm{~g}$ de Delsterol (Vit. D), $1.300 \mathrm{~g}$ de farinha de ostra e $600 \mathrm{~g}$ de sal por $100 \mathrm{~kg}$ de mistura.

\section{4 - RESULTADOS}

Os pesos obtidos nos diferentes períodos encontram-se no Quadro II. Do início ao fim de 2 semanas morreram. um pinto no Grupo A e 2 pintos nos demais. Entre 2 e 4 semanas morreu mais um pinto no Grupo A, ficando todos os Grupos com 43 pintos. Houve, pois, uma mortalidade uniforme de $4,4 \%$.

A análise de variância dos pêsos dos pintes no início do en. saio (Quadro III) demonstrou não ter importância estatística as diferenças de pêso médio observadas entre os grupos usados, que podiam ser considerados equivalentes. $O$ mesmo entretanto não se verificou no fim do ensaio, quando a média dos pesos dos dois grupos que receberam farinha de rami superou em 46,3g $(8,5 \%)$ os grupus que receberam farinha de fêno de alfafa. Como se pode observar da análise de variância do Quadro III (b), a diferença deve ser considerada bastante significativa em favor dos grupos que consumiram farinha de rami.

O consumo de ração foi de $143 \mathrm{~kg}$ para os dois grupos A e de 150 para os dois grupos $\mathrm{B}$, o que deu um índice de eficiência para os primeiros de $3,33 \mathrm{~kg}$ de ração por $\mathrm{kg}$ vivo para os lotes A e A' e $3,20 \mathrm{~kg}$ para os lotes B e B', números êsses considerados normais para a idade. Embora o experimento não tivesse sido planejado para permitir a análise estatística da eficiência das rações, o indício é de ser, também neste sentido, superior, a ração contendo farinha de rami.

Os pintos de todos os lotes apresentaram bom desenvolvimento e boa aparência, não revelando sinais evidentes de qualquer carência. 


\section{QUADRO II}

F'êso médio por pinto (em gramas) no início do ensaio e aos 14, 28 e 42 dias

(A e A', lotes que receberam Alfafa. B e B', lotes que receberam Rami)

\begin{tabular}{ccccc}
\hline Lotes & Início & 2 semanas & 4 semanas & 6 semanas \\
\hline A & 39,5 & 110,1 & 283,0 & 537,4 \\
A' & 40,3 & 118,8 & 295,1 & 542,8 \\
Média & 39,9 & 114,5 & 289,1 & 540,1 \\
B & 40,6 & 122,6 & 310,7 & 579,3 \\
B' & 41,6 & 125,3 & 323,7 & 593,5 \\
Média & 40,9 & 124,0 & 317,2 & 586,4 \\
\hline
\end{tabular}

\section{QUADRO III}

(a) Pesagem inicial (pintos de 1 dia).

Análise da variância

\begin{tabular}{|c|c|c|c|c|}
\hline & G. L. & S. Q. & Q. M. & $\mathrm{F}$ \\
\hline $\begin{array}{l}\text { Entre grupos } \\
\text { Dentro de grupos }\end{array}$ & $\begin{array}{r}3 \\
176\end{array}$ & $\begin{array}{r}71,37 \\
2.398,30\end{array}$ & $\begin{array}{l}23,79 \\
13,63\end{array}$ & $\underline{1,74}$ \\
\hline Total & 179 & $2.469 .6 ?$ & - & - \\
\hline
\end{tabular}

Conclusão: Diferença não significativa entre os grupos. Êstes eram, portanto, bastante uniformes.

(b) Pesagem final (pintos de 42 dias).

Análise da variância

\begin{tabular}{c|r|r|r|r} 
& G. L. & S. Q. & Q. M. & F \\
\hline $\begin{array}{l}\text { Entre tratamentos } \\
\begin{array}{c}\text { Entre grupos dentro } \\
\text { de tratamentos }\end{array}\end{array}$ & 1 & $92.095,55$ & $92.095,55$ & $7,13^{* *}$ \\
$\begin{array}{c}\text { Dentro de tratamen- } \\
\text { tos }\end{array}$ & 168 & $2.168 .739,55$ & $12.909,16$ & - \\
\hline$\quad$ Total & 171 & $2.265 .776,75$ & - & - \\
\hline
\end{tabular}

Conclusão: Diferença altamente significativa entre tratamentos, a favor do grupo de pintos alimentados com farinha de fôlhas de rami. 


\section{5 - DISCUSSÃO}

Os resultados neste experimento vêm confirmar aquêles obtidos por MEHRHOF, DAVIS e DRIGGERS (1950). Os pesos médios não podem ser comparados por terem êsses autôres trabalhado com pintos da raça Leghorn Branca e apresentado os resultados de 11 semanas de idade. A eficiência da ração nes. se perícdo com 6 e $9 \%$ de farinha de rami foi respectivamente de 3,19 e 3,25 em contraste com 3,26 na que continha farinha de alfafa. Num segundo ensaio, acharam repectivamente $3,12 \in$ 3,17 para 3,16 na ração com farinha de alfafa, o que indicava que a ração com $6 \%$ de farinha de rami mostrou-se sempre ligeiramente mais eficiente que aquela com 6\% de farinha $\mathrm{N}$. alfafa. Os resultados por nós obtidos em 6 semanas, com ração de $5 \%$ de farinha de alfafa $(3,33)$ e a de $5 \%$ de farinha de rami $(3,20)$, revelam a mesma tendência.

Os pesos obtidos para as diferentes idades nos lotes de sexos misturados de raça pesada aproximam-se nos grupos B e B' de $600 \mathrm{~g}$, considerado normal para aves boas muito bem alimentadas. Os lotes A e A', recebendo farinha de fêno de alfafa, cieram pesos ligeiramente subnormais nas diferentes idades, embora superiores aos obtidos por MIRANDA (1958) para a raça New Hampshire. O bom desenvolvimento pəde ser atribuído em parte à boa estação do ano (inverno).

Embora não houvesse separação de sexos, sua proprry̧āo nos grupos não eram de molde a prejudicar os resultados, r... mo porque em raças pesadas, como a White American, näc há diferenças significativas entre sexos até a 6a. semana. Ais diferenças observadas nos pesos médios finais dos lotes que receberam farinha de alfafa $(537,4 \mathrm{~g}$ e $542,8 \mathrm{~g})$, em contraste com os que receberam farinha de rami $(579,3 \mathrm{~g}$ e $593,5 \mathrm{~g})$ revolaram um teste $\mathrm{F}$ bastante significativo, que não deixou dúvida em relação à superioridade da última. E' de se notar que as c nclusões dos autôres citados são pela equivalência dos dois produtos, enquanto que nós enconiramos vantagem na substituição. Isto talvez possa ser explicado pelo fato dêles terem empregado uma ração basal superior na qual entraram "solúveis secos de distilaria" e "sôro de leite sêco", enquanto nós preferimos usar rações mais simples, menos "completas" que pudessem acentuar as diferenças porventura existentes.

Tratando-se de uma forrageira muito mais fácil de ser cultivada que a alfafa, no Estado de São Paulo, embora bastante 
exigente quanto à fertilidade do solo, e apresentando o mesmo valor, senão superior, os autôres, diante dos resultados obtidos, recomendam a farinha de rami como sucedâneo da de altafa. Considerando que os ponteiros e as fôlhas não são atualmente aproveitados devidamente, acreditam que, industrializados $\lambda$ ra abastecimento das fábricas de ração, venham a constitị $x$ uma fonte de renda tão importante como a fibra, que constiui o principal objetivo da cultura. O Norte do Paraná e o Estado de São Paulo já possuem extensas culturas desta planta. que —encontrada mais esta larga aplicação - tenderá a expanriirse de maneira apreciável.

\section{6 - RESUMO E CONCLUSÕES}

Os AA. fizeram um ensaio de competição, com replicação, no qual foram utilizados 180 pintos da raça White American. substituindo $5 \%$ de farinha de fêno de altafa por igual quantidade de farinha de fôlhas de rami, um subproduto da cultura desta planta.

Os grupos que receberam farinha de rami, no fim de 6 semanas mostraram-se mais pesados (579,3 e 593,5 g) que os alimentados com ração contendo farinha de fêno de alfafa $(537,4$ e $542,8 \mathrm{~g})$. A análise de variância revelou ser uma diferença altamente significante.

Sendo a farinha de rami uma subproduto da cultura dessa planta para a produção de fibra, os AA. acreditam que seu emprêgo venha a se generalizar quando os fabricantes de ração e criadores tenham conhecimento dêstes resultados.

\section{7 - ABSTRACT}

The ramie leaf meal was used in a feeding trial, in comparison with alfalfa hay meal in the range of $5 \%$ of the ration. Each lot consisted of two pens of 45 White American chicks was raised in batteries for 6 weeks.

From results of the analisis of variance the AA. concluded for the superiority of the ramie leaf meal $(586,4 \mathrm{~g})$ over the alfalfa hay meal $(540,1 \mathrm{~g})$ in the conditions of the experiment. 


\section{8 - BIBLIOGRAFIA}

MEHRHOF, N. R., G. K. DAVIS e J. C. DRIGGERS, $1950-$ Ramie Meal in Chick Rations, Circ. S-20, Univ. of Florida, Agric. Exp. St., Gainesville, Fla. pp. 5.

MIRANDA, R. M., 1958 - Contribuição ao aperfeiçoamento da técnica de Experimentação com pintos em crescimento. Tese de Concurso. E. N. V. da Univ. Rural, Rio de Janeiro, pp. 64.

MORRISON, F. B., 1950 - Feeds and Feeding, 21a ed., The Morrison Publishing Company, Ithaca, N. Y.

\section{9 - AGRADECIMENTOS}

Os AA. agradecem a contribuição do prof. Tufi Coury pela análise da amostra do material utilizado, ao prof. E. Malavolta, pela análise de caroteno, à Secção de Nutrição Animal do D.P.A., pelo fornecimento de dados analíticos de farinha de rami. 